\title{
Spinal Osteoid Osteoma Associated With Soft Tissue Changes as a Challenging Diagnosis: A Review of the Literature
}

\author{
Feyza Karagoz Guzey, ${ }^{1, *}$ Burak Eren, ${ }^{1}$ Azmi Tufan, ${ }^{1}$ Ozgur Aktas, ${ }^{1}$ and Abdurrahim Tas ${ }^{1}$ \\ ${ }^{1}$ Bagcilar Training and Research Hospital, Neurosurgery Clinic, Istanbul, Turkey \\ ${ }^{*}$ Corresponding author: Feyza Karagoz Guzey, Bagcilar Training and Research Hospital, Neurosurgery Clinic, Istanbul, Turkey. Tel: +90-5326334032, E-mail: fkarag@yahoo.com \\ Received 2015 November 30; Accepted 2016 January 2.
}

\begin{abstract}
Context:Spinal osteoid osteoma $(\mathrm{OO})$ is an infrequent tumor and due to both its smallness and complex anatomy of the spine diagnosis is challenging. In addition, associated undefined soft tissue changes on magnetic resonance imaging(MRI) frequently cause misdiagnosis. Evidence Acquisition: PubMed database was searched for "spinal osteoid osteoma" and larger clinical series related to clinical pictures, diagnosis or treatment modalities, and also case reports with especially soft tissue changes and related to special treatment modalities were introduced to the study. It was aimed at to make conscious practitioners of clinical and diagnostic characteristics of spinal OOs. Results: Spinal OOs constitute about $10 \%$ of OOs and the most of the tumors are seen in adolescents or young adults. The most frequent clinical picture is painful scoliosis or torticollis according to the level of the tumor. On MRI that is the most frequently performed imaging modality in the patients with painful scoliosis, undefined extensive bone and soft tissue changes is quite frequent. Clinicians must be aware from these findings and they must suspect and investigate the patients with bone scintigraphy and thin sectioned computerized tomography that both of them together can show presence of the lesion and provide to determine exact location of the lesion. Despite the increasing number of the studies using percutaneous ablation techniques, standard treatment of spinal OOs is still intralesional excision. Surgical excision usually provides immediate pain relief, and recurrence is not frequent.

Conclusions: Diffuse paravertebral muscle and soft tissue involvement having resemblance to myositis is not quite rare in the patients with spinal OO. This may be the sole finding on MRI and it must be alert for the clinicians to look for small OO nidus by bone scintigraphy or thin sectioned CT scan.
\end{abstract}

Keywords: Osteoid Osteoma, Spinal Tumor, Soft Tissue

\section{Context}

Osteoid osteoma (OO) is a benign bone tumor consisting of a bone nidus surrounded by a fibrovascular tissue and separated from normal bone tissue with a dense sclerotic bone margin (1). It was first reported by Bergstrand in 1930 (2) and it was defined as a different entity by Jaffe in 1935 (3). Osteoid osteoma is a relatively frequent tumor and it constitutes $10.8 \%$ to $13.5 \%$ of all primary benign bone tumors (2). However, spinal involvement is infrequent and in only about $10 \%$ of cases the tumor was located in the spine (4).

Because $\mathrm{OO}$ is a small tumor and spine has a complex anatomy, diagnosis is very difficult when this tumor is located in the spine, especially in cases with perinidal soft tissue changes.

\section{Evidence Acquisition}

Searching PubMed for "spinal osteoid osteoma" resulted in 503 articles. All of them were evaluated for clinical characteristics, diagnosis, differential diagnosis, treatment modalities, pathological characteristics, and outcome, particularly for associated soft tissue changes on MRI. Larger clinical series related to clinical pictures, diagnosis or treatment modalities, and also case reports with especially soft tissue changes and related to special treatment modalities were introduced to the study.

In this article, clinical and radiological characteristics and treatment modalities of spinal OOs are discussed and particularly associated paravertebral soft tissue changes are reviewed. It was aimed at to make conscious clinicians of clinical and diagnostic characteristics of spinal OOs.

\section{Results}

\subsection{Incidence, Location and Demographic Characteristics}

Although $\mathrm{OO}$ is a relatively frequent tumor that constitutes over $10 \%$ of all benign bone tumors, it is infrequently located in the spine, and only under $10 \%$ of the lesions occur in the spine $(2,5)$. In a study from pathology laboratory of a big university hospital, only 8 out of 131 OOs were located in the spine or sacrum (6.1\%)(5). Therefore, spinal 00

Copyright ( ) 2016, Iran University of Medical Sciences. This is an open-access article distributed under the terms of the Creative Commons Attribution-NonCommercial 4.0 International License (http://creativecommons.org/licenses/by-nc/4.0/) which permits copy and redistribute the material just in noncommercial usages, provided the original work is properly cited. 
series are usually small and largest series in literature consist of 5 to 81 cases (4-10). Ben Abdallah et al. (11) reported 44 spinal $\mathrm{OO}$ or osteoblastoma (OB) cases from radiology archive of their hospital and they reviewed 421 additional cases in literature, and 191 of them had spinal 00.

Osteoid osteoma usually occurs in the first 3 decades of life and $90 \%$ of the patients are younger than 25 years. However, there are a few older patients in literature (12). Osteoid osteoma has been reported in patients ranging from 2 to 56 years of age (13). It has a male predominance and a male/ female ratio of at least 2:1 (2).

Spinal OOs are most commonly located in the lumbar followed by cervical and thoracic spine. They rarely occur in the sacrum $(7,14)$. However, Gasbarrini et al. (15) showed a homogeneous distribution of pathological levels in a study of 81 cases with 28 in the lumbar, 27 in the thoracic and 26 in the cervical regions. The most commonly affected part of the vertebrae is the neural arch in $75 \%$ of cases, with $33 \%$ involving the lamina, $20 \%$ involving the articular facets, and 15\% involving the pedicles (16). Pars interarticularis is the most common (73\%) site of involvement (7). In only $10 \%$ of the cases, they are located in the vertebral body (17).

\subsection{Clinical Picture}

\subsubsection{Pain}

Most common clinical picture of spinal OOs is nontraumatic back or neck pain in a young patient. However, a few painless cases have been reported (18). Frequently, scoliosis or torticollis associates to the pain according to the level of the lesion. Two of the important characteristics of this pain are to increase at night and to relieve by oral salicylic acid or other nonsteroidal anti-inflammatory drugs (NSAID) (2). It is classically unrelated to activity (14), and is initially dull, throbbing, and intermittent and becomes more intense and knifelike over time (19). It is thought that this pain is caused by the presence of nerve endings and production of prostaglandins in the nidus $(20,21)$. The production of prostaglandin may lead to an increase in vascular pressure, which may produce pain by stimulating afferent nerves around the nidus (20). This explains the responsiveness of $\mathrm{OO}$ to salicylates or other NSAIDs (15). Positive response to salicylates is reported in a range of $14 \%$ - $90 \%$ in literature (7), and it could be used as a diagnostic clue (20). Some authors suggest that the cause of synovitis and nonspecific arthritis that occurred in the OOs located adjacent joints is also prostaglandin release from osteoma. Duman et al. (22) reported a sacral OO located adjacent the sacroiliac joint causing pain mimicking sacroiliitis.

The average duration of pain is about 15 to 20 months in several studies, but it may be up to 68 months (7). This delay is usually due to not to call to mind of $\mathrm{OO}$ in differential diagnosis. Therefore, practitioners who are responsible for diagnosis and treatment of general symptoms and signs in young patients need to be aware of the pos- sibility of $\mathrm{OO}$ in persistent spinal pain especially when associated with scoliosis (7).

Radicular pain is not frequently seen in the cases with spinal $O O$ in contrary to the patients with spinal OB. However, in some patients long standing abdominal or thorax wall pain or pelvic pain mimicking sacroiliitis may be unique symptom according to the level of the lesion (22, 23). In the series by Ozaki et al. (24) 2 of 9 cases and in the series by Raskas et al. (25) 7 of 11 patients had radicular pain. Spinal cord and nerve root compression is absent in most cases with radicular pain (26). Radicular pain may be related to inflammation around the nerve root. Zenmyo et al. (26) reported two cases with radicular pain due to peritumoral inflammation that was histologically verified around the nerve root. Large amounts of prostaglandin E2 and prostacyclin released from the nidus may be related to the isolated root irritation (21). Neurological deficits are also extremely rare in spinal 00 (27).

\subsubsection{Scoliosis}

Painful scoliosis is a very frequent symptom of spinal 00. Scoliosis is reported in 70\% of the cases and spinal 00 is the most common cause of painful scoliosis in adolescents $(2 / 3)(1,16)$. However, most patients with adolescent scoliosis have little or no pain. The curves are usually concave to the affected site (1). However, Saifuddin et al. (28) reported 3 cases with convex side lesions in their archive and literature review consisting 465 spinal $\mathrm{OO}$ and OB cases.

Scoliosis is considered to be secondary to muscle spasm and inflammatory changes of the adjacent soft tissues on the side of the lesion (1). It was demonstrated that asymmetrically located lesions in the thoracic or lumbar spine are associated with the greatest risk of developing scoliosis (28). Scoliosis may be due to muscle spasm secondary to an inflammatory reaction around the tumor (29). Assoun et al. (29) reported that $63 \%$ of the cases were associated with inflammatory changes in surrounding soft tissues. Aydinli et al.(1) explained absence of scoliosis in some spinal $O O$ cases with absence of inflammatory changes around the tumor.

Scoliosis resulting from spinal OO was observed to be more pronounced in lumbar vertebra involvement and was more severe in youths than in adults (6). Also, when the fourth or fifth lumbar vertebra is involved, it was generally associated with pelvic obliquity (17). Kyphosis in spinal $\mathrm{OO}$ also may be produced by destructive lesions that cause wedge collapse of the vertebral body. Conversely, hyperlordosis has been described as a consequence of symmetric posterior muscle spasm (1).

After tumor removal, scoliosis is usually relieved spontaneously. However, Ransford et al. (30) reported that scoliosis may be structural and may not improve after surgery in the patients with long duration of the symptoms ( $>15$ months). They postulated that the concave-side muscle spasms will eventually cause asymmetric growth inhibition of the vertebral epiphysis, leading to a rotational deformity and the curve to become structural (30). Zileli e al. 
(4) reported that only one case was required for scoliosis treatment among their 16 patients with spinal $O O$ and $O B$.

\subsubsection{Diagnosis}

In spinal OOs, diagnosis is usually possible with thin sectioned detailed computerized tomography (CT), magnetic resonance imaging (MRI) and radionuclide bone scan. However, delay of diagnosis or misdiagnosis is very frequent because they are small lesions and spine has a very complex anatomy.

\subsubsection{Bone Scanning}

Very early diagnosis can be provided by isotope scanning in all cases of unexplained spinal pain and/or spasm. Even in the cases whose initial CT scan is normal, the nidus can be seen by bone scanning, and a repeated thin sectioned ( 2 $\mathrm{mm}$ ) CT can show the lesion (31). Although there are some cases who had false negative bone scanning in literature (32), bone scan has high sensibility in diagnosis of OO, but low specificity (22). Particularly, spondylolysis, another frequently seen lesion in young population, may cause misdiagnosis (33). Presence of double density sign is more specific to $\mathrm{OO}$ in differentiation from spondylolysis (22). This sign is characterized by a focal hot spot of the nidus and an area of low peripheral radionuclide accumulation in the perinidal sclerotic bone. Bone scintigraphy has been advocated to localize the vertebral level in young patients with clinically suspected $\mathrm{OO}$, with subsequent targeted CT examination to define the nidus.

\subsubsection{Computerized Tomography}

Computed tomography can be helpful both in localizing the lesion in a single vertebra and for better definition of the lesion. This modality is more accurate than MR imaging in detecting the nidus of OO. If plain radiographs and bone scan were negative, it was reported that CT could be helpful for diagnosis and this was not uncommon with spine and pelvic lesions $(1,33)$.

The tumor usually appears as a round and expansile lesion with reactive sclerosis in the surrounding bone. Its nidus contains thick internal trabecular bone embedded within a low-density matrix (2). The nidus is radiolucent on radiographs and low attenuation on CT because it contains numerous osteoblasts with fibrous tissue richly supplied by blood vessels that are larger than normal (34). Perinidal sclerosis is an important finding for OO. Harish and Saifuddin(33) reported that it was seen in 12 of 13 cases.

\subsubsection{Magnetic Resonance Imaging}

The nidus usually appears low to intermediate in signal on $\mathrm{T} 1$ and variable on $\mathrm{T} 2$ weighted images if it can be seen in the middle of the edema of adjacent bone and soft tissues and reactive sclerotic bone $(2,14)$. Focal signal void due to matrix mineralization may be seen (33). The lesion usually enhances after contrast administration, however, in some cases it may not enhance (2). However, the nidus is often obscured by the tremendous surrounding edema (14). Davies et al. (35) reported a 65\% accuracy of MRI in diagnosis of spinal OOs. Therefore, MRI has been considered to produce misleading appearances and cause diagnostic errors due to the presence of associated soft tissue mass, bone marrow edema and joint effusion by some authors (33). However, at the present times, MRI is usually the first preferred investigation method for the cases with back and neck pain because of its noninvasiveness and harmlessness thanks to that it is free from radiation in contrary to bone scanning and CT. Therefore, clinicians treating those patients with spinal symptoms without evident signs should be aware of MRI findings of spinal OOs. If we know these signs on MRI, we can suspect the presence of $\mathrm{OO}$ and we can diagnose the lesion by bone scanning or CT (1). When the small nidus is overlooked, paravertebral inflammatory changes may be misdiagnosed as inflammatory or malignant lesions; and the patients may undergo multiple long-term therapies for relief of pain, including unnecessary surgeries or biopsies (1). Guzey et al. (34) reported such a patient who was misdiagnosed as a neoplastic lesion and be subjected to an unnecessary soft tissue biopsy.

Perilesional bone or soft tissue intensity changes in spinal $O O$ are very frequent (1). On MRI, intensity changes probably due to edema in both adjacent bone and soft tissues may be seen (33). The presence of extensive perinidal edema is thought to be due to high levels of cyclo-oxygenase-2 expression in neoplastic osteoblasts in the nidus (33). This condition may be interpreted as reflecting the reactive nature of these lesions. Reactive periosteal bone formation, nonspecific proliferative synovitis, and intimal fibromuscular proliferation in arteries adjacent to the $\mathrm{OO}$ nidus may also be viewed as other manifestations of this phenomenon (34). Yamamura et al. (36) found that the grades of peritumoral soft tissue reaction on MRI was correlated with elevated prostaglandin levels in some benign and malignant bone tumors such as chondroblastoma, chondrosarcoma, osteochondroma and $\mathrm{OB}$.

Bone edema may extend through a few spinal levels, and posterior element involvement is distinctive probably due to more frequently posterior location of OOs. Harish et al. (33) reported that bone edema was seen as unilateral neural arch edema in 8 out of 13 patients, and they postulated that the presence of unilateral neural arch edema extending to involve the posterolateral vertebral body on MRI raises the possibility of spinal $O O$ and should prompt CT to confirm the presence of a nidus. These changes may extend through a few levels, and soft tissue changes may affect both paravertebral soft tissues and also nerves. Gokce et al. (37) reported a case with $\mathrm{T} 1$ OO causing $\mathrm{C} 7$ to $\mathrm{T} 2$ nerve roots involvement and brachial neuralgia. In cases with intense and extensive edema, misdiagnosis is frequent (33).

Soft tissue changes on MRI in cases with spinal OO were first reported by Woods et al. (38) in three cases in 1993. 
After them, this condition was mentioned in detail in only case reports $(26,34,39-42)$. Although bony and soft tissue changes are relatively frequent in these cases, unfortunately, large series of spinal 00 in literature were mainly interested in treatment of lesions and they did not mention MRI findings in detail, especially soft tissue changes $(5-10,15)$. Harish et al. (33) reported MRI findings of a series consisting of 13 patients. They reported the presence of adjacent bone edema in 11 cases and soft tissue changes in 4 cases. Ozaki et al. (24) mentioned that areas of high signal intensity due to perilesional edema were seen on the T2-weighted images in 9 of 10 patients, however they did not mention that how much of them soft tissue changes were seen in.

Perilesional soft tissue changes may be seen in other bony tumors such as chondroblastoma, chondrosarcoma, osteochondroma and OB (36). Crim et al. (43) also reported a case with spinal $O B$ had similar soft tissue changes on MRI.

\subsubsection{Misdiagnosis and Differential Diagnosis}

Rate of misdiagnosis in spinal oOs is very high. Pourfeizi et al. (6) reported 54.5\% misdiagnosis. Etemadifar et al. (7) reported in only 1 misdiagnosed case out of 19 cases, however, delay of diagnosis in their series was remarkable and duration of pain was 4 - 56 months (mean 15.1 months).

Most important lesion in differential diagnosis of $\mathrm{OO}$ is OB that they differentiated from each other according to their size rather than the histological patterns. Osteoid osteoma is smaller than 1.5 centimeters in diameter and OB is larger $(1,37)$. Osteoblastoma prefer spine to locate more frequently than $\mathrm{OO}$. About $50 \%$ of OB cases are located in spine. Also, $\mathrm{OB}$ is less painful and when pain in present, it is not as severe at night and usually does not respond the salicylate treatment as was the pain of $\mathrm{OO}(4,40)$. In the WHO classification of tumors of soft tissue and bone, $\mathrm{OO}$ and $\mathrm{OB}$ continue to be listed as separate entities because it was reported a positive identification of innervation in OOs, but not in OBs by previous light microscopy (44) and immunohistochemistry (29) studies. However, Barlow et al. (3) evaluated immunohistochemical characteristics of $10 \mathrm{OO}$ and $20 \mathrm{OB}$ and they demonstrated innervations of both tumor types. The authors concluded that both $\mathrm{OO}$ and $\mathrm{OB}$ share novel histomorphological and immunohistochemical features, they offer a pathogenetic explanation for their apparent clinical and radiological variance. Barrow et al. (3) speculated that where an 'OO/OB' arises within the cortex, its growing capacity is restricted both by the surrounding dense compact cortical bone and its closeness to the richly innervated periosteum resulting in relatively early clinical presentation with pain. Conversely, where the 'lesion' arises in medullary bone, it is able to attain a larger size as it is less constricted by the medullary trabecular bone, and is at a distance from the richly innervated periosteum enabling pain-free growth to occur for a longer period of time. According to the authors, this view would also explain the difference in age of clinical presentation between $\mathrm{OO}$ and $\mathrm{OB}$ that there was over a decade for the ages of clinical presentations. Another finding in literature supporting this view is that Cappuccio et al. (45) reported a case with an OO progressing to $\mathrm{OB}$ on the right $\mathrm{C} 6$ pedicle one year later.

Other lesions that must be kept in mind in differential diagnosis of $\mathrm{OO}$ are aneurismal bone cyst, giant cell tumor of bone, degenerative disc disease, facet joint diseases, previous trauma, malignancies and spondylolysis $(1,37,40)$. Particularly, spondylolysis may be frequently confused with $\mathrm{OO}$ because it is seen in similar age group and in similar location in vertebra. In addition, it causes enhancement on bone scintigraphy as to be in OO. However, perilesional bone edema is not distinctive on MRI in contrary to the $\mathrm{OO}$ (37). Pedicle bone marrow edema does not extend into the vertebral body in spondylolysis cases in contrary to $\mathrm{OO}(33)$.

\subsubsection{Pathology}

Osteoid osteoma is characterized by a nidus that may originate in the cortical, cancellous, or subperiosteal regions of a bone. The cortical (classical) type of $\mathrm{OO}$ is the most common one, while the cancellous and subperiosteal types are less frequent (2). Spinal OOs are usually in cortical type.

They are small tumors and are usually under $2 \mathrm{~cm}$ in size. In Zileli et al. series, the diameters of spinal OOs were 1.5 to $2 \mathrm{~cm}$ (mean $1.7 \mathrm{~cm}$ ) (4). Usually, a sclerotic rim surrounded the nidus is observed (4). The tumor size and presence of sclerotic rim are important features to differentiate the OOs from OBs (37).

Histologically, the nidus is a well-circumscribed lesion composed of osteoid tissue containing irregular islets with an irregular network of osteoid trabeculae, varying degrees of calcification, and a highly vascularized stroma rich in cells (34). This nidus is often surrounded by a rim occurring from reactive bone formation (2).

Findings of histological examination of reactive soft tissue changes were reported in a few cases in literature. Woods et al. (38) reported marked skeletal muscle atrophy and prominent swollen endothelium including intimal fibromuscular proliferation in histological examination, and Guzey et al. (34) reported a chronic inflammatory reaction without neoplastic cells.

\subsubsection{Treatment}

Possible treatment modalities of spinal OOs range from a long-term NSAID therapy to surgery. The disease can be self-limiting, and pain may be relieved after 2 - 8 years of conservative medical treatment because the nidus matures into bone tissue $(1,2,17)$. The pain responds well especially to salicylate, even scoliosis may spontaneously resolve by this therapy (34). However, this may take several years and the side effects of chronic NSAIDs may 
be much more than surgery (14). In rare adult patients, surgery is recommended if conservative treatment with NSAIDs fails (19). However, in younger patients, the lesion is usually treated with surgical excision because of the risk that the compensatory scoliosis may become structural (19). However, conservative treatment may also be performed in selected young patients with close followup. Jayakumar et al. (13) reported a 10 year old girl with T6 OO. She was treated with NSAIDs and she became entirely asymptomatic 16 months later. Her scoliosis was also abolished. Qiao et al. (20) reported another case with $O O$ located in the dens of axis. They treated the patient with follow-up and medical treatment with celecoxib. After 2 years the patient was asymptomatic.

In some patients nonoperative treatment fails, or some patients may not tolerate a long-term NSAI therapy. In this condition surgical treatment is necessary. Surgical options in these patients are open resection or percutaneous techniques such as radiofrequency (RF) thermal ablation and laser coagulation. Experience with percutaneous techniques in extraspinal OOs is quite much; however, in spinal lesions they may be dangerous because of proximity of the lesions to the neural tissues (16). They may be the first choice if the lesion location is appropriate. Small series with good clinical results are increasing in literature in last decade $(17,19,46-48)$. However, there are some drawbacks for these treatment types. Gangi et al. (10) recommended that percutaneous RF ablation should be contraindicated in spinal oOs if the nidus is $<$ $5 \mathrm{~mm}$ from neurological structures because of the risk of thermal injury. Dasenbrock et al. (49) reported that plasma mediated RF ablation may allow with a decreased risk of thermal injury to neural structures compared with traditional RF or interstitial laser ablation.

Despite the increasing number of the studies using percutaneous RF techniques, standard treatment of spinal OOs is still intralesional excision. This may be provided by standard microscopic surgery, or by guidance of some technology such as CT guidance (50), video-assisted endoscopy (15) or navigation (51) according to the location of the lesion. The goal of OO surgery is to remove the nidus entirely without causing pathologic fracture, especially facets and pedicles or disrupting the adjacent uninvolved tissues (7). Complete resection of OOs may require extensive removal of the posterior spinal elements, including the facet joints, in this condition fusion and stabilization may be required (49). Gasbarrini et al. (15) reported that 5 of their 81 cases (6.1\%) and Etemadifar et al. (7) reported that 4 of their 19 cases (21\%) needed fusion and stabilization. In addition to instability, other surgery related complications such as vertebral artery injury, delayed rupture of a vertebral artery, and spontaneous fusion with deformity were reported(51).

\subsubsection{Outcome}

Surgical excision usually provides immediate pain relief (14). Recurrence is not frequently seen, especially in the cases whose tumors are removed totally (7). Resection of the lesion remains the best option for achieving a cure and complete resection produces long-term remission in up to $95 \%$ of cases $(2,7)$. In the cases with scoliosis or torticollis, the curves usually heal spontaneously $(4,7,25)$.

\section{Conclusions}

Spinal OOs are not frequently seen tumors. They usually occur in young patients and cause painful scoliosis or torticollis according to their location. However, in the most commonly seen scoliosis type of young patients, idiopathic scoliosis, pain is generally absent. Therefore, painful scoliosis in young patients, especially if pain is aggravated at night, spinal OO must be thought. Diffuse paravertebral muscle and soft tissue involvement having resemblance to myositis is not quite rare in these patients and this may be the sole finding on MRI. In this circumstance, small OO nidus must be looked for by the bone scintigraphy or thin-sectioned CT scan.

\section{Footnote}

Authors' Contribution:Study concept and design: Feyza Karagoz Guzey, and Burak Eren; acquisition of data: Ozgur Aktas, and Abdurrahim Tas; analysis and interpretation of data: Feyza Karagoz Guzey, Burak Eren, Azmi Tufan, and Ozgur Aktas; drafting of the manuscript: Feyza Karagoz Guzey, and Burak Eren; critical revision of the manuscript for important intellectual content: Feyza Karagoz Guzey; administrative, technical, and material support: Azmi Tufan, Ozgur Aktas, and Abdurrahim Tas; study supervision: Feyza Karagoz Guzey.

\section{References}

1. Aydinli U, Ozturk C, Ersozlu S, Filiz G. Results of surgical treatment of osteoid osteoma of the spine. Acta Orthop Belg. 2003;69(4):350-4. [PubMed:14526641]

2. Amirjamshidi A, Roozbeh H, Sharifi G, Abdoli A, Abbassioun K. Osteoid osteoma of the first 2 cervical vertebrae. J Neurosurg. 2010;13(6):707-14. doi: 10.3171/2010.5.spine09297.

3. Barlow E, Davies AM, Cool WP, Barlow D, Mangham DC. Osteoid osteoma and osteoblastoma: novel histological and immunohistochemical observations as evidence for a single entity. $J$ Clin Pathol. 2013;66(9):768-74. doi: 10.1136/jclinpath-2013-201492. [PubMed: 23814261]

4. Zileli M, Cagli S, Basdemir G, Ersahin Y. Osteoid osteomas and osteoblastomas of the spine. Neurosurg Focus. 2003;15(5):E5.

5. Yalcinkaya U, Doganavsargil B, Sezak M, Kececi B, Argin M, Basdemir G, et al. Clinical and morphological characteristics of osteoid osteoma and osteoblastoma: a retrospective single-center analysis of 204 patients. Ann Diagn Pathol. 2014;18(6):319-25. doi: 10.1016/j.anndiagpath.2014.08.006. [PubMed:25224389]

6. Pourfeizi HH, Tabrizi A, Bazavar M, Sales JG. Clinical findings and results of surgical resection of thoracolumbar osteoid osteoma. Asian Spine J. 2014;8(2):150-5. doi: 10.4184/asj.2014.8.2.150. [PubMed: 24761196]

7. Etemadifar MR, Hadi A. Clinical Findings and Results of Surgical Resection in 19 Cases of Spinal Osteoid Osteoma. Asian Spine J. 2015;9(3):386-93. doi:10.4184/asj.2015.9.3.386. [PubMed:26097653]

8. Klass D, Marshall T, Toms A. CT-guided radiofrequency ablation of spinal osteoid osteomas with concomitant perineural and epidural irrigation for neuroprotection. Eur Radiol.2009;19(9):223843. doi: 10.1007/s00330-009-1404-8. [PubMed: 19387650] 
9. Vanderschueren GM, Obermann WR, Dijkstra SP, Taminiau AH Bloem JL, van Erkel AR. Radiofrequency ablation of spinal osteoid osteoma: clinical outcome. Spine (Phila Pa 1976). 2009;34(9):9014. doi:10.1097/BRS.0b013e3181995d39. [PubMed: 19360000]

10. Gangi A, Alizadeh H, Wong L, Buy X, Dietemann JL, Roy C. Osteoid osteoma: percutaneous laser ablation and follow-up in 114 patients. Radiology. 2007;242(1):293-301. doi: 10.1148/radiol.2421041404. [PubMed:17090708]

11. Ben Abdallah N, Sarrazin JL, Soulie D, Cosnard G. [Spinal osteoid osteoma, neuralgia and MRI]. J Radiol.1996;77(2):133-6. [PubMed: 8729342]

12. Cheng YP, Chen CM, Lin PY. Osteoid osteoma on the way of pedicle screw insertion for spinal fusion. Spine J. 2015;15(1):196-7. doi: 10.1016/j.spinee.2014.08.451. [PubMed: 25200327]

13. Jayakumar P, Harish S, Nnadi C, Noordeen H, Saifuddin A. Symptomatic resolution of spinal osteoid osteoma with conservative management: imaging correlation. Skeletal Radiol. 2007;36 Suppl 1:S72-6. doi:10.1007/s00256-006-0198-x. [PubMed:16967288]

14. Anderson ME. Spinal tumors found in the athlete. Clin Sports Med. 2012;31(3):569-80. doi: 10.1016/j.csm.2012.03.001. [PubMed: 22658002]

15. Gasbarrini A, Cappuccio M, Bandiera S, Amendola L, van Urk P, Boriani S. Osteoid osteoma of the mobile spine: surgical outcomes in 81 patients. Spine (Phila Pa 1976). 2011;36(24):2089-93. doi:10.1097/BRS.0b013e3181ffeb5e. [PubMed: 21304430]

16. Campos WK, Gasbarrini A, Boriani S. Case report: Curetting osteoid osteoma of the spine using combined video-assisted thoracoscopic surgery and navigation. Clin Orthop Relat Res. 2013;471(2):680-5. doi: 10.1007/s11999-012-2725-5. [PubMed: 23212772]

17. Cristante AF, Barros Filho T, Oliveira RP, Barbarini AF, Teixeira WG. Treatment of osteoid osteoma in the vertebral body of the lumbar spine by radiofrequency ablation. Clinics (Sao Paulo) 2007;62(6):791-4. [PubMed:18209922]

18. Jackson RP, Reckling FW, Mants FA. Osteoid osteoma and osteoblastoma. Similar histologic lesions with different natural histories. Clin Orthop Relat Res.1977;(128):303-13. [PubMed: 598169]

19. Hadjipavlou AG, Tzermiadianos MN, Kakavelakis KN, Lander P. Percutaneous core excision and radiofrequency thermo-coagulation for the ablation of osteoid osteoma of the spine. Eur Spine J. 2009;18(3):345-51. doi: 10.1007/s00586-008-0791-x. [PubMed: 19031087]

20. Qiao J, Zhu F, Zhu Z, Liu Z, Qian B, Qiu Y. Conservative treatment for osteoid osteoma of the odontoid process of the axis: a case report. World J Surg Oncol. 2014;12:305. doi: 10.1186/1477-7819-12-305. [PubMed: 25287277]

21. Greco F, Tamburrelli F, Ciabattoni G. Prostaglandins in osteoid osteoma. Int Orthop. 1991;15(1):35-7. [PubMed: 2071279]

22. Duman I, Aydemir K, Tan AK, Dincer K, Kalyon TA. An unusual case of osteoid osteoma clinically mimicking sacroiliitis. Clin Rheumatol. 2007;26(7):1158-60. doi: 10.1007/s10067-006-0280-8. [PubMed: 16738842]

23. Dhaliwal HS, Makkar DS, Gowda KK. A curious case of abdominal pain relieved by aspirin. Gastroenterology. 2014;147(4):745-8. doi: 10.1053/j.gastro.2014.04.057. [PubMed: 25158028]

24. Ozaki T, Liljenqvist U, Hillmann A, Halm H, Lindner N, Gosheger $\mathrm{G}$, et al. Osteoid osteoma and osteoblastoma of the spine: experi ences with 22 patients. Clin Orthop Relat Res. 2002;(397):394-402. [PubMed: 11953633]

25. Raskas DS, Graziano GP, Herzenberg JE, Heidelberger KP, Hensinger RN. Osteoid osteoma and osteoblastoma of the spine. J Spinal Disord. 1992;5(2):204-11. [PubMed: 1606380]

26. Zenmyo M, Yamamoto T, Ishidou Y, Komiya S, Ijiri K. Osteoid osteoma near the intervertebral foramen may induce radiculopathy through tumorous inflammation. Diagn Pathol. 2011;6:10. doi: 10.1186/1746-1596-6-10. [PubMed: 21247497]

27. Kaner T, Sasani M, Oktenoglu T, Aydin S, Ozer AF. Osteoid osteoma and osteoblastoma of the cervical spine: the cause of unusual persistent neck pain. Pain Physician. 2010;13(6):549-54. [PubMed: 21102967]

28. Saifuddin A, White J, Sherazi Z, Shaikh MI, Natali C, Ransford AO. Osteoid osteoma and osteoblastoma of the spine. Factors associated with the presence of scoliosis. Spine (Phila Pa 1976). 1998;23(1):47-53. [PubMed: 9460152$]$

29. Assoun J, Richardi G, Railhac JJ, Baunin C, Fajadet P, Giron J, et al. Osteoid osteoma: MR imaging versus CT. Radiology. 1994;191(1):217-23. doi: 10.1148/radiology.191.1.8134575. [PubMed: 8134575

30. Ransford AO, Pozo JL, Hutton PA, Kirwan EO. The behaviour pattern of the scoliosis associated with osteoid osteoma or osteoblastoma of the spine. J Bone Joint Surg. 1984;66(1):16-20.

31. Yamamoto K, Asazuma T, Tsuchihara T, Motosuneya T, Tsuji T, Fujikawa K, et al. Diagnostic efficacy of thin slice CT in osteoid osteoma of the thoracic spine: report of two cases.J Spinal Disord Tech. 2005;18(2):182-4. [PubMed:15800438]

32. Kong J, Xiao H, Liu T, Yan W, Qian M, Song DW, et al. The valuation of using FDG PET-CT in detecting osteoid osteoma of the cervical spine. J Spinal Disord Tech. 2015;28(2):E67-73. doi:10.1097| BSD.0000000000000146. [PubMed:25093651]

33. Harish S, Saifuddin A. Imaging features of spinal osteoid osteoma with emphasis on MRI findings. Eur Radiol. 2005;15(12):2396403. doi: 10.1007/s00330-005-2816-8. [PubMed:15973540]

34. Guzey FK, Seyithanoglu MH, Sencer A, Emei E, Alatas I, Izgi AN Vertebral osteoid osteoma associated with paravertebral soft-tissue changes on magnetic resonance imaging. Report of two cases. J Neurosurg. 2004;100(5 Suppl Pediatrics):532-6. doi: 10.3171/ ped.2004.100.5.0532. [PubMed:15287469]

35. Davies M, Cassar-Pullicino VN, Davies AM, McCall IW, Tyrrell PN The diagnostic accuracy of MR imaging in osteoid osteoma. Skeletal Radiol. 2002;31(10):559-69. doi: 10.1007/s0 0256-002-0546-4. [PubMed: 12324824]

36. Yamamura S, Sato K, Sugiura H, Katagiri H, Ando Y, Fukatsu H, et al. Prostaglandin levels of primary bone tumor tissues correlate with peritumoral edema demonstrated by magnetic resonance imaging. Cancer. 1997;79(2):255-61. [PubMed: 9010098]

37. Gokce E, Ayan E, Celikyay F, Acu B. Radiological imaging findings of a case with vertebral osteoid osteoma leading to brachial neuralgia. J Clin Imaging Sci. 2013;3:54. doi: 10.4103/2156-7514.122324. [PubMed: 24404413]

38. Woods ER, Martel W, Mandell SH, Crabbe JP. Reactive soft-tissue mass associated with osteoid osteoma: correlation of MR imaging features with pathologic findings. Radiology. 1993;186(1):2215. doi: 10.1148/radiology.186.1.8416568. [PubMed: 8416568]

39. Zanetti M, Eberhard SM, Exner GU, von Hochstetter A, Hodler J [Magnetic resonance tomography in osteoid osteoma: more confusion than benefit?]. Praxis (Bern 1994). 1997;86(11):432-6. [PubMed: 9190645]

40. Sukan A, Kabatas S, Cansever T, Yilmaz C, Demiralay E, Altinors N. Osteoid osteoma in the thorasic spine. Turk Neurosurg. 2009;19(3):288-92. [PubMed: 19621297]

41. Kawahara C, Tanaka Y, Kato H, Watanabe S, Kokubun S. Myolysis of the erector spinae muscles as the cause of scoliosis in osteoid osteoma of the spine. Spine (Phila Pa 1976). 2002;27(12):E313-5. [PubMed: 12065996]

42. Lefton DR, Torrisi JM, Haller JO. Vertebral osteoid osteoma masquerading as a malignant bone or soft-tissue tumor on MRI. Pediatr Radiol.2001;31(2):72-5. doi:10.1007/s002470000378. [PubMed 11214688]

43. Crim JR, Mirra JM, Eckardt JJ, Seeger LL. Widespread inflammatory response to osteoblastoma: the flare phenomenon. Radiology. 1990;177(3):835-6. doi: 10.1148/radiology.177.3.2243998. [PubMed 2243998]

44. O'Connell JX, Nanthakumar SS, Nielsen GP, Rosenberg AE. Osteoid osteoma: the uniquely innervated bone tumor. Mod Pathol. 1998;11(2):175-80. [PubMed: 9504688]

45. Cappuccio M, De Iure F, Amendola L, Corghi A, Gasbarrini A Cervical osteoid osteoma progression to osteoblastoma. Spine J. 2014;14(6):1070-1. doi: 10.1016/j.spinee.2013.12.021. [PubMed: 24445325]

46. Morassi LG, Kokkinis K, Evangelopoulos DS, Karargyris O, Vlachou I, Kalokairinou K, et al. Percutaneous radiofrequency ablation of spinal osteoid osteoma under CT guidance. Br J Radiol. 2014;87(1038):20140003. doi: 10.1259/bjr.20140003. [PubMed 24712322] 


\section{Karagoz Guzey F et al.}

47. Rehnitz C, Sprengel SD, Lehner B, Ludwig K, Omlor G, Merle C, et al. CT-guided radiofrequency ablation of osteoid osteoma and osteoblastoma: clinical success and long-term follow up in 77 patients. Eur J Radiol. 2012;81(11):3426-34. doi: 10.1016/j. ejrad.2012.04.037. [PubMed: 22770580]

48. Weber MA, Sprengel SD, Omlor GW, Lehner B, Wiedenhofer $\mathrm{B}$, Kauczor HU, et al. Clinical long-term outcome, technical success, and cost analysis of radiofrequency ablation for the treatment of osteoblastomas and spinal osteoid osteomas in comparison to open surgical resection. Skeletal Radiol. 2015;44(7):981-93. doi: 10.1007/s00256-015-2139-z. [PubMed: 25910709]
49. Dasenbrock HH, Gandhi D, Kathuria S. Percutaneous plasma mediated radiofrequency ablation of spinal osteoid osteomas. J Neurointerv Surg. 2012;4(3):226-8. doi: 10.1136/neurintsurg-2011-010054. [PubMed: 21990513]

50. Fukuda S, Susa M, Watanabe I, Nishimoto K, Horiuchi K, Toyama $\mathrm{Y}$, et al. Computed tomography-guided resection of osteoid osteoma of the sacrum: a case report. J Med Case Rep. 2014;8:206. doi:10.1186/1752-1947-8-206. [PubMed: 24942997]

51. Nagashima H, Nishi T, Yamane K, Tanida A. Case report: osteoid osteoma of the $\mathrm{C} 2$ pedicle: surgical technique using a navigation system. Clin Orthop Relat Res. 2010;468(1):283-8. doi:10.1007| s11999-009-0958-8. [PubMed:19568822] 